\title{
DESEMPENHO DAS EXPORTAÇÕES DO MELÃO POTIGUAR E CEARENSE: uma análise de constant market share
}

Thales Augusto Medeiros Penha ${ }^{1}$; Helderlane Carneiro Alves ${ }^{2}$.

\begin{abstract}
Resumo
O comércio internacional de frutas frescas apresentou um crescimento considerável nas últimas décadas. O Brasil se destaca no comércio de algumas frutas, sendo o melão um dos principais players. No entanto, nos últimos anos, observa-se uma dinâmica competitiva entre os dois principais estados produtores, estes revezaram na liderança como principal região exportadora. Deste modo, este trabalho analisa a competitividade e a inserção das exportações do melão brasileiro, a partir da análise dos dois principais estados produtores, Ceará e Rio Grande do Norte, durante o período de 1993 a 2013. Para isto, utilizou-se o método Constant Market Share, esta metodologia permite analisar a inserção de países/regiões no comércio internacional e as fontes de crescimento das exportações separando em três componentes: crescimento global, expansão dos mercados de destino e competitividade. Os resultados indicam que o crescimento efetivo das exportações do melão cearense foi determinado pela maior competitividade. Já no caso potiguar, apesar do fator competitividade ter tido importância em alguns períodos, o crescimento do comércio mundial foi uma das principais fontes de crescimento efetivo.
\end{abstract}

Palavras-chave: Exportações de melão; Competitividade; Constant Market Share.

\footnotetext{
${ }^{1}$ Professor do Departamento de Economia na Universidade Federal do Rio Grande do Norte (UFRN). Doutor em Desenvolvimento Econômico pelo Instituto de Economia da Universidade Estadual de Campinas (Unicamp). Mestrado e graduação em Economia pela Universidade Federal do Rio Grande do Norte.

${ }^{2}$ Mestranda do Programa de Pós-Graduação em Administração da UFRN. Bacharel em Ciências Econômicas pela UFRN.
} 


\title{
THE PERFORMANCE OF MELON PRODUCED IN RIO GRANDE DO NORTE AND CEARÁ STATES: a constant market share analysis
}

\begin{abstract}
The International trade of the fresh fruits has grown considerably in the last few decades. Brazil stands out in the trade of some fruits, among them the melon in which Brazil is one of the main players. However, in recent years there has been a competitive dynamic between the two main producing states, which took the lead as the main exporting region. Thus, this work analyzes the competitiveness and insertion of Brazilian melon exports, based on the analysis of the two main producing States, Ceará and Rio Grande do Norte, during the period 1993 to 2013. For this, the method Constant Market Share was adopted, this methodology allows analyzing the insertion of regions in international trade and the sources of export growth, separating into three components: global growth, expansion of destination markets and competitiveness. The results indicate that the effective growth of the exports of the melon of Ceara was determined by the greater competitiveness. In the Potiguar case, although the competitiveness factor was important in some periods, the growth of world trade was one of the main sources of effective growth.
\end{abstract}

Keywords: International Trade of melons; Constant Market Share.

JEL: Q10; Q13; Q17.

\section{Introdução}

Os produtos agrícolas tradicionais da agricultura brasileira (açúcar, café, cacau e algodão), que durante muito tempo se destacaram na pauta de exportações brasileira, vêm apresentando uma queda na participação no total comercializado desde o final da década de 1980. Tais produtos eram responsáveis por $70 \%$ das exportações totais da agroindústria no início da década de 1970 e passaram a contribuir com menos de $30 \%$ no final da década de 1980 (JANK, 1990 apud JUNIOR et al., 2012). Em grande medida, esta queda no percentual total do volume exportado se deu devido ao crescimento da importância da soja brasileira a partir dos anos 1980, todavia outros produtos apresentaram crescimento importante, como os do grupo de Frutas, Legumes e Verduras (FLV). 
A partir da década de 1990, ocorreu um crescimento nas exportações brasileiras em decorrência da maior abertura comercial e estabilização monetária do país. Por sua vez, nos anos 2000, o crescimento foi alavancado pelo aumento da demanda mundial (MARANHÃO; VIEIRA FILHO, 2016). Diante desses acontecimentos, os produtos agrícolas brasileiros têm se destacado no mercado externo, mas sua ascensão também está relacionada aos ganhos de produtividade e competitividade, tais como o aumento da mecanização, a introdução de novas tecnologias voltadas para a agricultura, novas técnicas de produção e investimento em conhecimentos agrícolas (MARANHÃO; VIEIRA FILHO, 2016).

O consumo mundial de frutas frescas apresentou uma importante evolução nos últimos anos, o que permitiu a inserção das frutas brasileiras no mercado internacional. Alguns autores apontam que esse crescimento decorreu de algumas modificações, tais como mudança de postura do consumidor, surgimento de novas tecnologias, redução dos subsídios agrícolas, alterações nos padrões de produção, mudanças institucionais, entre outros fatores. Esses motivos impactaram na ascensão da demanda mundial por frutas frescas e possibilitou a introdução das frutas brasileiras no mercado mundial (PENHA, 2018; FUNCKE et al., 2009; WILKINSON, 2008).

É diante deste cenário que o melão brasileiro ganha destaque no comércio internacional. $\mathrm{O}$ melão apresentou o melhor desempenho na pauta comercial nacional dentre todas as frutas no ano de 2013, tanto em volume como em receita. De acordo com dados do Aliceweb foram exportados no ano de 2013 um total de 191,41 mil toneladas de melões, representando $27 \%$ das frutas brasileiras enviadas ao exterior. E neste mesmo ano, o Ceará (CE) e o Rio Grande do Norte (RN) foram os estados brasileiros que mais contribuíram para a sua produção e exportação.

No entanto, apesar dos dois estados atualmente disputarem o primeiro lugar como principais exportadores, durante os anos 1990 e início dos anos 2000. O Rio Grande do Norte era responsável por cerca de $80 \%$ das exportações nacionais. Todavia a partir dos anos 2000 o estado do Ceará passou a crescer sua participação no volume exportador, chegando a ultrapassar o Rio Grande do Norte no final da década de 2010. Diante deste cenário, indagam-se as seguintes questões de pesquisa: quais foram os fatores que impactaram na dinâmica competitiva no mercado internacional do melão? Quais foram as principais diferenças na trajetória da produção de melão no Rio Grande do Norte e Ceará? 
Para responder tais perguntas, utilizou-se o método Constant Market Share (CMS) que permite decompor os fatores que impactam na dinâmica comercial de uma dada região. A partir dos resultados obtidos pelo procedimento, podem-se mensurar os efeitos do crescimento global do comércio, crescimento dos mercados de destino da produção da região e efeitos de competitividade. Atualmente este método vem sendo aplicado em diversos trabalhos que buscam analisar a competitividade e parcela de mercado de diversos produtos brasileiros (soja, camarão, melão etc) no mercado mundial (PENHA; OLIVEIRA, 2015; DORNELES; CALDARELLI, 2014; OLIVEIRA, 2014; SILVA; MARTINS, 2012; FIGUEIREDO et al. 2004). Os resultados apresentados por Penha \& Oliveria (2015) apontam para os ganhos de competitividade do estado do Rio Grande do Norte nas últimas duas décadas. No entanto, os autores destacam aspectos macroeconômicos, como câmbio e alterações geopolíticas que favoreceram a inserção potiguar no comércio internacional. Assim, este trabalho analisando o crescimento do Ceará no período recente a taxas superiores a do Rio Grande do Norte busca identificar fatores internos que tem impactado em trajetórias diferentes, bem como, relativizar o cenário externo em função de demais aspectos que envolvem a competitividade. $O$ período analisado compreende os anos de 1993 a 2013, a restrição a tal período se deve à disponibilidade de dados, o FAOSTAT no período da coleta de dados só dispunha de dados até o ano de 2013.

Este artigo tem como objetivo analisar a competitividade e a inserção das exportações do melão brasileiro, a partir da análise dos dois principais estados produtores, Ceará e Rio Grande do Norte, durante o período de 1993 a 2013. A cultura do melão. Além desta, este trabalho está estruturado em quatro partes: a primeira tem o objetivo de analisar como ocorreu a trajetória do melão na região nordestina, especificamente nos principais estados; a segunda parte demonstra os procedimentos metodológicos adotados; a terceira parte apresenta os resultados obtidos; e por fim, constam as considerações finais.

\section{A Trajetória da Produção do Melão na Região Nordeste}

A introdução do melão na região Nordeste só foi possível devido à implementação de polos irrigados constituídos através de investimentos públicos e privados. As obras de infraestrutura hídrica na região permitiram a irrigação de vastas extensões de terras que foram utilizadas, principalmente, para a produção de frutas destinadas ao mercado externo. Diante disso, a seguir será abordada a trajetória da cultura do melão nos dois maiores estados produtores da região Nordeste e do Brasil, atualmente, Rio Grande do Norte e Ceará que também se destacam como maiores exportadores e são responsáveis por inserir o Brasil entre os maiores exportadores de melão no cenário internacional. 


\subsection{A Cultura do Melão no Rio Grande do Norte}

O Rio Grande do Norte além de ser o maior produtor do melão brasileiro, destacase nas exportações de melão, liderando o ranking, como pode ser observado no Gráfico 1, até o ano de 2007, perdendo a liderança para o Ceará no ano de 2008. A forte queda no ano de 2008 foi consequência da crise internacional que atingiu diretamente os produtores, em função da queda na demanda por melões dos países europeus (PENHA, 2018). O RN, antes de 2008, contribuiu com mais de $60 \%$ das exportações nacionais, ultrapassando os $80 \%$ de contribuição no período de 1994 a 2000.

Gráfico 1 - Exportações do melão potiguar (Mil toneladas)

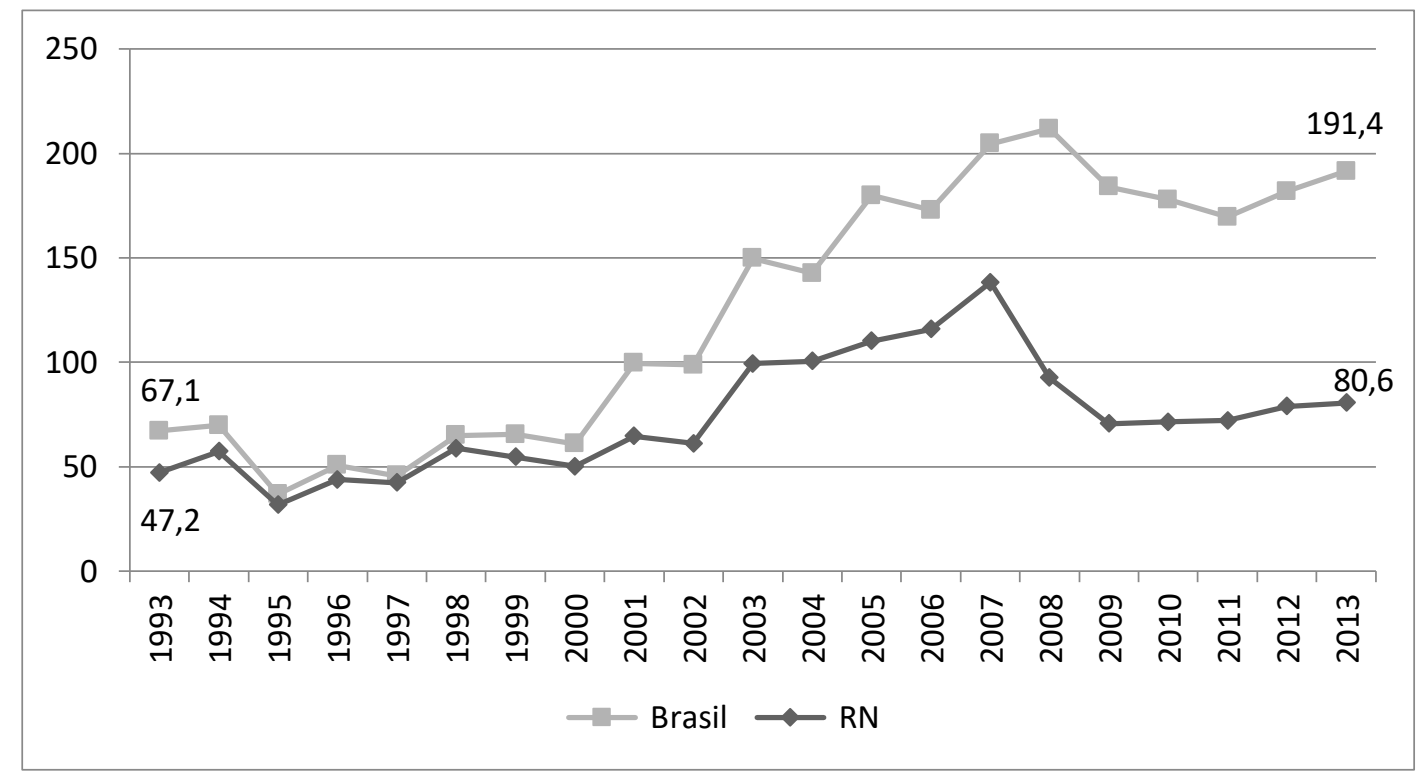

Fonte: Elaboração própria, a partir de dados do ALICEWEB/MDIC

Em 2008, ocorreu uma diminuição na quantidade exportada de 45,8 mil toneladas. Essa queda está relacionada à crise econômica internacional iniciada no mês de setembro de 2008, que coincidiu com o período de safra brasileiro (agosto a setembro). Em decorrência desse cenário negativo, na tentativa de suavizar o impacto da crise, os produtores de melão buscaram um novo destino, aumentando suas vendas no mercado interno (CELIN et al., 2014; PENHA, 2018). 
O estabelecimento do estado do Rio Grande do Norte como uma área importante de produção de frutas para o mercado internacional deve-se, segundo Nunes e Schneider (2008), ao processo de modernização ${ }^{3}$ da agricultura do estado implementado entre as décadas de 1970 e 1980 que permitiu alterar a dinâmica produtiva do setor. Antes deste processo, a produção agropecuária do estado era marcada pela baixa intensidade tecnológica. No entanto, esse cenário se modifica a partir dos anos 1970 quando foram desenvolvidos os projetos de irrigação para implementação de projetos agrícolas modernos.

Este processo obteve êxito a partir da combinação de tecnologias modernas, acesso aos mercados e o esforço do Estado de criar um ambiente atrativo para instalação de empresas. O Estado foi o principal protagonista de efetuação deste movimento, mediante investimentos em infraestrutura básica, principalmente em relação ao acesso a recursos hídricos. No caso do Rio Grande do Norte, a principal obra é a construção da Barragem Engenheiro Armando Ribeiro Gonçalves, que permitia a irrigação da região do Vale do Rio Açú. Além da infraestrutura hídrica o Estado Nacional ofertava abundantemente crédito subsidiado (fundos especiais obtidos através das políticas regionais direcionadas). Tais políticas asseguravam os elementos essenciais para implementação de projetos produtivos.

Esses incentivos de modernização realizados pelo Estado foram direcionados, principalmente, para o Vale do Açu e a região de Mossoró, o que permitiu o surgimento do Polo Açú-Mossoró. Estes investimentos tinham o objetivo de modernizar a produção agropecuária do Rio Grande do Norte, a partir da criação de um setor agroindustrial constituído por empresas processadoras de produtos agrícolas, além de ativar a indústria de insumos agrícolas modernos. Portanto, tinha-se por trás a ideia de um polo dinâmico com encadeamentos para trás e para frente da produção agrícola (NUNES, 2009).

Com a mudança conjuntural da economia brasileira em meados da década de 1980, devido à crise da dívida externa e a deterioração da situação físcal (VASCONCELLOS et al., 1999; CARNEIRO, 2002), ocorre uma inflexão na política agrícola de apoio aso polos, como detalha Silva (2001). Neste novo contexto, os polos agrícolas da região passaram a sofrer com o fim dos incentivos fiscais. Além do mais, devido à necessidade de diminuir o déficit nas contas externas, há um forte incentivo de promoção a exportação dos produtos agrícolas. Neste novo cenário, passou-se a promover a exportação do setor agrícola o que permitiu a inserção de produtos brasileiros no

${ }^{1} \mathrm{O}$ desenvolvimento da região através de grandes projetos incentivados pelo Estado, o qual estimulou a criação e o desenvolvimento de mercados (terras, tecnologias, trabalho etc.). A partir dos anos 1980 ocorreu um aumento na intensidade dos investimentos nas regiões de Mossoró e Açú, e os mercados se desenvolveram mais fortemente, alterando a estrutura fundiária e as relações de produção e trabalho, gerando desconexões do capitalismo (PLOEG, 1995), as quais destroem localidades e seus mecanismos de regulação (NUNES; SCHNEIDER, 2008). 
mercado internacional. Assim, após esta série de investimento e novo quadro macroeconômico nacional, emerge a fruticultura irrigada voltada para a exportação no Rio Grande do Norte. Esta se consolida baseada na produção principalmente do melão no início dos anos 1990 na região do Polo Açú-Mossoró.

Todavia, como demonstram Nunes e Schneider (2008), o Polo Açú-Mossoró sofreu um grande desafio nos anos 2000, em decorrência do Programa de Certificação EUREPGAP, além de ter que enfrentar a abertura de comércio e a ausência de incentivos do Estado, bem como alterações estruturais do mercado de trabalho. O EUREPGAP foi um instrumento internacional de controle de qualidade que tinha a finalidade de monitorar e rastrear os produtos agrícolas à distância, criado pelos varejistas europeus. Em decorrência dessas exigências de qualidade proposto pelo programa, as grandes empresas do polo, MAISA e FRUNORTE, foram incapazes de continuar a produção e anunciaram falência em 2002 e 2003, respectivamente. Além dessas exigências de qualidade, a mudança estrutural da forma de trabalho também apresentou um impacto importante no regime dessas empresas, em decorrência da maior fiscalização do Ministério do Trabalho sobre a legislação trabalhista aliada ao movimento sindical da região de produção de frutas, onde houve um processo de formalização na mão de obra utilizada, ao passo que grande parte delas se sustentava com regime de trabalho informal e sofreram para adaptar suas escalas de produção a essa nova exigência (Penha et al., 2018).

Neste novo cenário do início dos anos 2000, caracteriza-se por uma intensificação da mecanização, mudanças nas relações de trabalho, surgimento de novas técnicas de irrigação e da introdução de novas técnicas no processo de produção, como os mulchings, destacado por Oliveira (2011), que consiste em cobrir o solo para proteger e prepará-lo. Esses fatores vêm proporcionando um grande avanço na produtividade de melões por hectare. Este quadro apesar de trazer profundas transformações no ambiente não significou uma depressão na produção do Polo porque ao mesmo tempo em que ocorreram as falências das duas mais proeminentes empresas da região (MAISA e FRUNORTE) surgiram outras empresas que aproveitaram a herança tecnológica e o know-how dos negócios ${ }^{4}$. Segundo Penha (2016), esses novos agentes aproveitaram o conhecimento existente e agregaram novos padrões técnicos que permitiram maiores ganhos de produtividade, mesmo com a redução da área plantada.

\footnotetext{
4 Essa incorporação do Know-how dos negócios e a herança tecnológica foram absorvidas por estas novas empresas, pois elas foram fundadas por técnicos agrícolas que trabalhavam dentro das empresas pioneiras do melão, especialmente na MAISA. Assim, estes técnicos, após a falência, adquirem terras e passam a produzir sob este novo ambiente, e assim, de forma global a produção do melão não é afetada.
} 
Oliveira (2011) explica que a área geográfica onde se localizava a produção de melão se deslocou no sentido Oeste do estado, passando de Açú para Mossoró, e mais recentemente, abrangendo o município de Baraúna. Esse deslocamento ocorreu em decorrência da falência das grandes empresas, da ausência de investimento na produção e da rotatividade de cultura e aparecimento de pragas dentro do solo. Desta maneira, a produção do melão não tem se concentrado no perímetro irrigado do Baixo Açú, a produção nessa região praticamente não existe mais e a água vem sendo obtida através de poços, muitas vezes profundos, ocasionando um alto custo de energia para bombear a água, não sendo mais abastecida pela barragem Armando Ribeiro.

\subsection{A Cultura do Melão no Ceará}

O Ceará, assim como o Rio Grande do Norte, destaca-se no Brasil na produção e exportação do melão. No entanto, foi somente a partir dos anos 2000 que o Ceará começou a figurar como um importante produtor nacional. Diante deste desempenho, o estado consolidou-se como segundo maior produtor de melão do país e, assim, passa a "rivalizar" com o estado do Rio Grande do Norte.

Observa-se no Gráfico 2, as exportações do melão cearense, entre 1993 e 2000, não passavam das 8 mil toneladas, de modo que sua participação nas exportações brasileiras não chegava a $10 \%$. No entanto, esse cenário mudou após os anos 2000, no qual obteve uma exportação de 28,7 mil toneladas em 2001 e alcançou uma participação de $55 \%$ nos melões brasileiros exportados no ano de 2008, ultrapassando o RN, até então líder nas exportações brasileiras. Após 2008 a participação cearense nas exportações brasileiras foram superiores a 55\%, demonstrando cada vez mais sua importância no cenário nacional.

Gráfico 2 - Exportações do melão cearense (Mil toneladas)

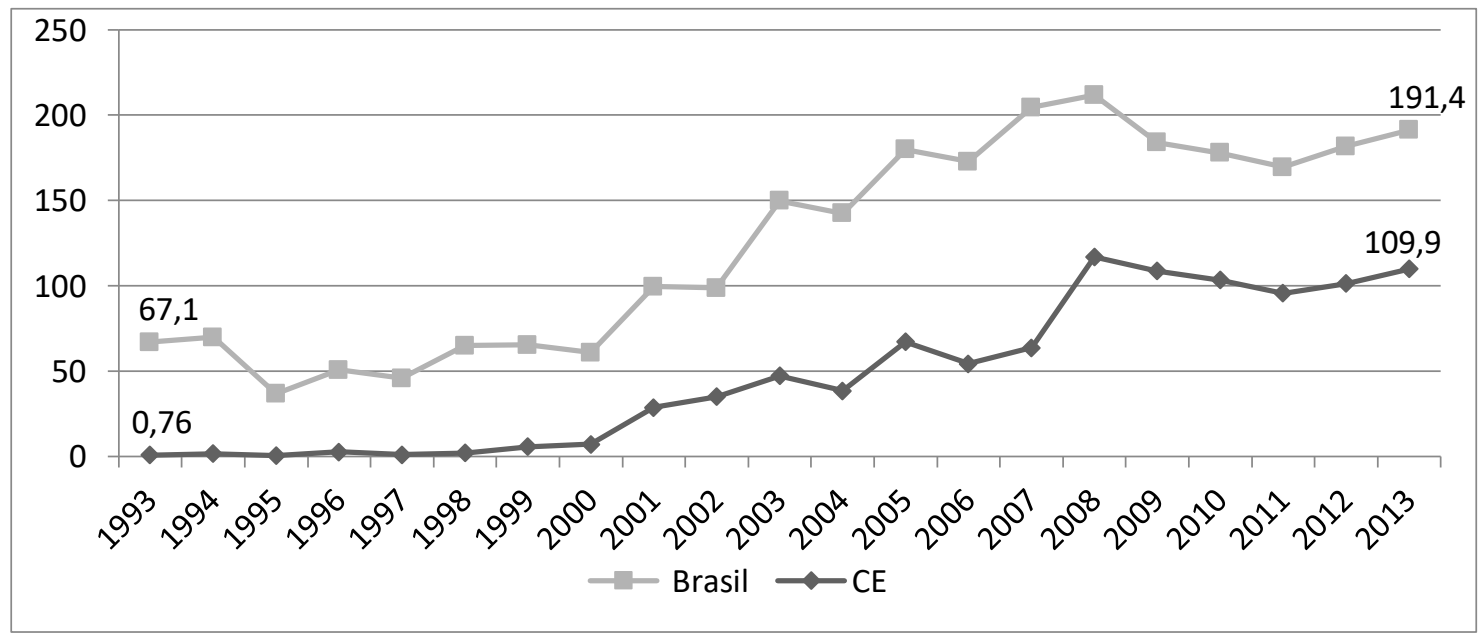

Fonte: Elaboração própria, a partir de dados do ALICEWEB/MDIC. 
Para entender esta ascensão da fruticultura do Ceará, é necessário recuperar os investimentos feitos a partir da década de 1960, nos mesmos moldes que permitiu a promoção do Rio Grande do Norte, como destacado na seção anterior. No caso do estado do Ceará, a produção de fruticultura foi possibilitada pelo desenvolvimento dos perímetros irrigados na região Baixo Jaguaribe, a partir da parceria entre o Grupo de Estudos do Vale do Jaguaribe (GEVJ), ligado à Superintendência do Desenvolvimento do Nordeste (SUDENE) e com o governo francês através do Instituto Francês de Pesquisa Cientifica para o Desenvolvimento em Cooperação (ORSTOM) (FERRÃO et al., 2014).

Na intenção de obter um mercado mais competitivo, com ganhos de produtividade melhoria nos produtos, os agentes cearenses (privados ou públicos) através de programas que incentivam a fruticultura irrigada, vêm promovendo investimentos em capacitação, gestão tecnológica, promoção comercial, infraestrutura e financiamento (SOARES, 2009).

No final da década de 1990, com a intenção de aumentar as exportações do melão brasileiro, foi implantado um sistema de Produção Integrada de Frutas (PIF), devido às exigências de qualidade imposta pelo mercado europeu. Já em 1999, a Secretaria de Agricultura Irrigada (SEAGRI) foi criada pelo governo do Ceará com o objetivo de colocar o Estado como referência internacional em agronegócios da agricultura irrigada competitiva e sustentável, líder na produção de produtos in natura e processados, gerando emprego e renda, além de fortalecer a Secretaria de Desenvolvimento Rural (SDR) (CEARÁ, 2000).

A partir de então, o estado cearense forneceu vários incentivos e criou diversas políticas públicas que foram direcionadas a cultura do melão cearense, com o objetivo de promover a produção e exportações do melão, tendo em vistas o desenvolvimento do estado. Além das ações já mencionadas, destacam-se: a ampliação do horário de energia subsidiada para os produtores rurais (passando de 23 horas às 6 horas do dia seguinte para 22 horas às 8 horas); a isenção de Imposto Sobre Circulação de Mercadorias e Serviços (ICMS)5 para a comercialização de produtos agrícolas internamente e externamente, e a eliminação do imposto de importação para equipamentos agrícolas; as linhas de créditos oferecidas pelo Banco do Brasil e Banco do Nordeste, uma das políticas mais importantes; treinamento para novos produtores, abordando técnicas modernas de produção (CENTEC - Centro de Treinamento Tecnológico, Programa de Qualidade Total Rural em Fruticultura); a formação de Grupos Integrados de Produtores, uma nova forma de organização da produção; sistemas "satélites" de produção, através das grandes empresas, ao fornecerem mercado final para os pequenos produtores; investimento em pesquisa e desenvolvimento na agricultura irrigada, uma participação de todos os agentes da cadeia produtiva (SOARES, 2009).

\footnotetext{
${ }^{5}$ Decorrente da Lei Kandir, aplicado em ambos estados, a qual isenta o exportador do ICMS, desta maneira, o estado devolve o ICMS pago pelo produtor no ato da exportação.
} 
Deste modo, o melão cearense vem se destacando ao longo dos anos em decorrência de sua relevante expansão, passando de uma participação de 1,13\% para $57,4 \%$ na quantidade exportada do melão nacional, durante o período analisado neste trabalho. Para Viana et al. (2008), esse desempenho positivo pode ser decorrente das condições internas favoráveis, como os incentivos governamentais para o desenvolvimento da agricultura irrigada, que estimulou investimentos na atividade com melhorias tecnológicas, capacitação de produtores, sendo relevante ressaltar ainda o efeito positivo proporcionado pela diminuição na carga tributária imposta ao produto a partir de 2001.

\subsection{Alguns traços gerais dos estados analisados}

De acordo com a literatura, o estado do Ceará forneceu mais estímulos para o desenvolvimento do melão, como a isenção no pagamento da água, a participação de todos os agentes na cadeia produtiva, a construção de várias estradas e a criação de secretarias para a fruticultura irrigada. Esses fatores podem ter influenciado na diferença de competitividade, analisado no item 4, existente nos dois estados.

Em ambos os estados, foi adotado a isenção do ICMS para a comercialização de produtos agrícolas internamente e externamente. Contudo, segundo o fundador da Agrícola Famosa, Luiz Roberto Barcelos, o estado do RN demora anos para devolver o valor do ICMS pago pelo produtor, diferentemente do estado cearense, que devolve imediatamente. Em tempos de crise tal agilidade atrai os produtores.

O fornecimento de água para a agricultura irrigada entre os estados é bem distinto. Enquanto no Ceará os produtores utilizam água do rio Jaguaribe, com diques e tubulações, no Rio Grande do Norte, a água provém de poços. Consequentemente, a obtenção de água no estado potiguar torna-se mais dispendiosa, pois necessita de maiores investimentos para obtê-las, porém, devido aos fatores naturais, como a seca, acaba transformando a água cearense em uma fonte sujeita a maiores incertezas. Acontecimento dessa natureza tem sido observado atualmente, pois algumas empresas cearenses vêm investindo em terras potiguares em decorrência da ausência de água no estado do Ceará para a produção do melão. 


\section{Metodologia}

\subsection{Delineamento e tipo de pesquisa}

O trabalho tem natureza explicativa sobre as fontes que atuaram nos últimos 20 anos na expansão do comércio internacional do melão, nos dois principais estados produtores do Brasil. Para isto, foram utilizados os tipos de pesquisas bibliográficas e documental na aquisição de dados secundários. A pesquisa bibliográfica foi realizada com o intuito de reunir elementos teóricos que fundamentaram a análise econômica do problema de pesquisa apresentado, bem como o desenvolvimento do modelo de análise utilizado. Para tal procedimento, foram consultados autores que abordam os aspectos centrais sobre o mercado agrícola internacional, mais especificamente sobre a fruticultura brasileira, destacando a cultura do melão nos estados do Rio Grande do Norte e Ceará. Por sua vez, a pesquisa documental foi utilizada para reunião de uma base de dados sobre a evolução do comércio internacional da fruticultura, com maior detalhamento da trajetória do melão produzido nos estados analisados neste trabalho. Tanto a coleta de dados como as revisões da literatura foram realizadas entre os meses de março e maio de 2017.

\subsection{Modelo de análise dos dados}

Para alcançar o objetivo deste trabalho, foi adotado o modelo Constant Market Share (CMS), modelo que permite identificar quais foram as causas que proporcionaram o crescimento (ou decrescimento) da participação das exportações do país/região " $x$ " em um referido período de tempo.

O modelo tem como premissa básica que a participação das exportações de determinado país no mercado mundial tende a permanecer constante entre dois períodos de tempo. Caso haja alteração, esta mudança pode ser explicada pelos seguintes fatores: a) crescimento do comércio mundial, efeito que indica qual seria o crescimento observado se as exportações evoluíssem na mesma taxa de crescimento das exportações mundiais, b) crescimento do destino, é representado pelos ganhos (ou perdas), em termo de percentagem de crescimento, pelo fato do país exportar para mercados que crescem a taxas superiores (ou inferiores) à média observada para todos os países, e c) competitividade, também conhecido como efeito residual, efeito que indica a porcentagem de crescimento dos ganhos (ou perdas) de participação das exportações do 
produto analisado nos diferentes mercados devido aos ganhos (ou perdas) de competitividade (SILVA; MARTINS, 2012).

Segundo Dorneles e Caldarelli (2014), o método Constant Market Share foi utilizado pela primeira vez por Tysynski (1951), um estudo sobre as mudanças no market share dos países nas exportações de bens manufaturados entre 1899 e 1950 . O modelo Constant Market Share foi aprimorado em outros estudos, os principais foram os trabalhos de Leamer e Stern (1970) e Richardson (1971). Atualmente este método vem sendo aplicado em diversos trabalhos que buscam analisar a competitividade e parcela de mercado de diversos produtos brasileiros (soja, camarão, melão etc) no mercado mundial (PENHA; OLIVEIRA, 2015; DORNELES; CALDARELLI, 2014; OLIVEIRA, 2014; SILVA; MARTINS, 2012; FIGUEIREDO et al. 2004).

A análise matemática do modelo Constant Market Share foi demonstrada por Silva e Martins (2012) onde citam Carvalho e Leite (2008). A formulação do modelo parte dos seguintes elementos:

Seja $V_{i t} \mathrm{O}$ valor total das exportações do país $i$ em determinado período $t$ :

$$
V_{i t}=\sum_{j=1}^{n} P_{i j t} \cdot Q_{i j t}
$$

Onde:

$P_{i j t}=$ preço do produto $\mathrm{j}$ exportado pelo país i no período final $\mathrm{t} ; \mathrm{e}$,

$Q_{i j t}=$ quantidade do produto $\mathrm{j}$ exportada pelo país i no período final t.

O valor total das exportações no período inicial (0) é:

$$
V_{i 0}=\sum_{j=1}^{n} P_{i j 0} \cdot Q_{i j 0}
$$

Desta maneira, o crescimento ocorrido no valor exportado entre o período inicial e final $\left(\Delta V_{i}^{0}\right)$ é:

$$
\Delta V_{i}^{0}=\sum_{j=1}^{n} P_{i j t} \cdot Q_{i j t}-\sum_{j=1}^{n} P_{i j 0} \cdot Q_{i j 0}
$$


Segundo Carvalho e Leite (2008), para analisar a competitividade do país $i$, foi necessário decompor a diferença entre o crescimento ocorrido nas exportações do país $i$ e o crescimento potencial, ou seja, como o crescimento teria ocorrido se as exportações do país $i$ tivessem o mesmo crescimento das importações mundiais.

Admite-se que $M_{w 0}$ e $M_{w f}$ sejam as importações mundiais no período inicial e final, respectivamente. Onde:

$$
\begin{aligned}
& M_{w 0}=\sum_{j=1}^{n} M_{w j 0} \\
& M_{w f}=\sum_{j=1}^{n} M_{w j f}
\end{aligned}
$$

A taxa de crescimento mundial das importações entre o período inicial e final pode ser representada pela seguinte equação:

$$
r_{i}=\frac{M w f}{M w 0}-1
$$

Da mesma maneira, obtém-se a taxa de crescimento das importações, por países, entre o período inicial e final:

$$
r_{i j}=\frac{M w j f}{M w j 0}-1
$$

Desta forma, se o crescimento potencial das exportações de i $\left(\Delta V_{i}^{0}\right)$ foi dado por:

$$
\Delta V_{i}^{0}=r_{i} \sum_{j=1}^{n} V_{i j}^{0}
$$


Portanto, se $\Delta V_{i}^{p}=\Delta V_{i}^{0}$ significa que o país manteve seu Market Share no mercado internacional. No entanto, se $\Delta V_{i}^{p} \neq \Delta V_{i}^{0}$, a diferença pode ser decomposta na seguinte equação:

$$
\sum\left(V_{i j}^{f}-V_{i j}^{0}\right)=\sum r_{i} V_{i j}^{0}+\sum\left(r_{i j}-r_{i}\right) V_{i j}^{0}+\sum\left(V_{i j}^{f}-V_{i j}^{0}-r_{i} j V_{i j}^{0}\right.
$$

Onde:

$\sum\left(V_{i j}^{f}-V_{i j}^{0}\right) \rightarrow$ representa o crescimento efetivo das exportações do produto $\mathrm{j}$;

$\sum r_{i} V_{i j}^{0} \rightarrow$ efeito do crescimento do comércio mundial;

$\sum\left(r_{i} \mathrm{j}-r_{i}\right) V_{i j}^{0} \rightarrow$ efeito destino;

$\sum\left(V_{i j}^{f}-V_{i j}^{0}-r_{i} j V_{i j}^{0}\right) \rightarrow$ efeito competitividade.

Como análise do Constant Market Share foi feita a partir da diferença entre períodos discretos foi prudente a agregação para evitar flutuações cíclicas que ocorre devido aos choques, e assim ter uma análise mais robusta e consistente com a evolução do comércio. Deste modo, deve-se analisar todo o período estudado e subdividi-lo em pequenas frações comuns que permitam ter uma melhor análise das trajetórias desenvolvidas pelo país ou região ao longo do tempo no comércio internacional (LEAMER; STERN, 2008).

Neste trabalhou analisou-se o comportamento das exportações de melão dos estados do Rio Grande do Norte e Ceará durante o período de 1993 a 2013. Este período justifica-se pelo fato do ano de 1993 ter marcado a ascensão do melão produzido no Nordeste no comércio internacional, e também, pela limitação da base de dados que até o momento da elaboração da análise empírica só possuía dados até o ano de 2013.

Deste modo, para aplicação do modelo Constant Market Share, observou-se nos estados do Rio Grande do Norte e Ceará sete subperíodos discretos no tempo com trajetórias que permitiam comparação dos desempenhos das quantidades exportadas dos dois estados minimizando os efeitos sazonais. Sendo assim, tem-se:

a) 1993-1995: abertura comercial dos países em relação ao comércio dos mercados agrícolas. E no ano de 1995 ocorreu o acordo da rodada do Uruguai. Portanto, este período compreende os anos que o mercado agrícola internacional ainda estava passando por um processo de destravamento via negociações multilaterais. 
b) 1996-1998: período pós-Rodada do Uruguai em que os mercados agrícolas, especialmente os de FLV apresentam importantes taxas de crescimento e integração (PENHA, 2016). Além disso, este período caracteriza-se pela taxa de câmbio apreciada em que variou entre 1,00 R\$ e 1,15R\$, já no ano de 1999 o câmbio salta para 1,81 em média.

c) 1999-2001: crescimento na produtividade da produção do melão, onde ambos os estados ultrapassaram as 20 toneladas por hectares. Período de mudanças internas importantes, em que antigas empresas pioneiras na produção de melão entram em decadência e abandonam o mercado (caso da Frunorte e Maisa no Rio Grande do Norte).

d) 2002-2004: valorização da taxa de câmbio em 2002, no qual alcançou 3,08 R \$ em média no ano de 2003 reais.

e) 2005-2007: período de apreciação cambial associado à alta dos preços dos alimentos, devido à forte dinâmica da economia chinesa (MARANHÃO \& VIERA FILHO, 2016)

f) 2008-2010: período marcado pela crise internacional de 2008 que resultou em quedas nas exportações, como também nos preços dos alimentos (MARANHÃO; VIEIRA FILHO, 2016)

g) 2011-2013: período de retomada pós-crise, com os preços dos alimentos no comércio mundial voltando a crescer.

Os mercados de destino foram sistematizados de modo a separar os principais países importadores dos estados, e os demais foram agregados por continentes. Deste modo os mercados destinos ficaram os seguintes: Espanha, Holanda, Reino Unido, Estados Unidos da América, Demais Europeus, Outros da América, África e Ásia (este continente só para o estado do Ceará). Esses países e continentes foram selecionados devido à relevância que eles apresentam nas exportações do melão para o Rio Grande do Norte e Ceará.

\subsection{Coleta de Dados}

Na coleta de dados foram utilizadas bases de dados públicas e disponíveis em sites na internet. As instituições pesquisadas foram as seguintes: Instituto Brasileiro de Geografia e Estatística (SIDRA/IBGE), Ministério de Desenvolvimento, Indústria e Comércio Exterior (ALICEWEB/MDIC), Secretaria de Comércio Exterior (SECEX) e Organização das Nações Unidas para Agricultura e Alimentação (FAOSTAT/FAO). 


\section{Análise dos Resultados}

\subsection{Decomposição das Fontes de Crescimento das Exportações de Melão no Rio Grande do Norte}

Tabela 1 - Síntese dos resultados da CMS do RN

\begin{tabular}{lcccc}
\hline \multicolumn{1}{c}{ Período } & $\begin{array}{c}\text { Crescimento } \\
\text { Efetivo }\end{array}$ & Competitividade & $\begin{array}{c}\text { Crescimento do } \\
\text { Comércio Mundial }\end{array}$ & Efeito Destino \\
\hline $\begin{array}{l}1993 / 95- \\
1996 / 98(\mathrm{I})\end{array}$ & $7,00 \%$ & $-275,25 \%$ & $675,26 \%$ & $-300,00 \%$ \\
\hline $\begin{array}{l}1996 / 98- \\
1999 / 01(\mathrm{II})\end{array}$ & $17,00 \%$ & $81,24 \%$ & $69,60 \%$ & $-50,85 \%$ \\
\hline $\begin{array}{l}1999 / 01- \\
2002 / 04(\mathrm{III})\end{array}$ & $54,00 \%$ & $70,41 \%$ & $23,16 \%$ & $6,44 \%$ \\
\hline $\begin{array}{l}2002 / 04- \\
2005 / 07(\mathrm{IV})\end{array}$ & $40,00 \%$ & $27,19 \%$ & $38,78 \%$ & $34,04 \%$ \\
\hline $\begin{array}{l}2005 / 07- \\
2008 / 10(\mathrm{~V})\end{array}$ & $-36,00 \%$ & $98,69 \%$ & $-5,90 \%$ & $7,20 \%$ \\
\hline $2008 / 10-$ & $-1,00 \%$ & $554,76 \%$ & $4,25 \%$ & $-459,00 \%$ \\
$2011 / 13$ & & & & \\
\hline
\end{tabular}

Fonte: Elaboração própria, a partir de dados do ALICEWEB/MDIC e FAOSTAT/FAO.

No primeiro subperíodo, o crescimento efetivo das exportações de melão foi da ordem de $7 \%$, tal resultado se deu pelo aumento significativo do comércio global do produto que ampliou em mais de $600 \%$ comparando o período 1996/98 ante 1993/95. Este significativo desempenho positivo do comércio mundial pode ser explicado pela consolidação do processo de abertura comercial firmado em 1995 na Rodada do Uruguai da Organização Mundial do Comércio. Nesse acordo, os produtos agrícolas eram o centro do debate que se arrastava desde meados dos anos 1980 (THORSTENSEN, 2003). Após a celebração do acordo, os países passaram a diminuir os subsídios agrícolas e relaxaram as medidas protecionistas para tais desencadeando um afrouxamento no comércio mundial, o que impulsionou o comércio de FLV (Frutas, Legumes e Verduras), principalmente as frutas tropicais (PENHA, 2018). 
É importante, também destacar que os demais fatores (competitividade e efeito destino) captados pelo método apresentaram sinais negativos, o que indica que tais reduziram o impacto deste crescimento global sobre o crescimento efetivo do marketshare potiguar no mercado internacional. O efeito destino apresentou uma queda de $300 \%$, o que significou que as exportações dos melões do RN perderam participação relativa nos seus principais parceiros no período. Como por exemplo, o caso da Holanda que, no período inicial, as exportações do RN representavam 33\% das importações de melão deste país, e, no período seguinte, esta participação reduziu para 30\%, mesmo com as importações da Holanda crescendo 13\%. Caso semelhante ocorre nas exportações destinadas ao Reino Unido que apresentou uma redução de participação de 1\%, mesmo com este país tendo expandido as importações em cerca de $30 \%$. Isto demonstra perda relativa de importância nos destinos, mesmo com o crescimento da demanda total. Por sua vez, o fator competitividade representou uma retração relativa de $275 \%$.

No segundo subperíodo, as exportações do melão do Rio Grande do Norte tiveram um crescimento de $17 \%$, neste período destaca-se o impacto do fator competitividade que apresentou uma expansão de 81,24\%. Segundo demonstram Belik et al. (2018), entre 1997 e 2001 houve um crescimento da produtividade do melão, passando de 16 toneladas por hectares para 25 toneladas por hectares. Segundo os autores, este ganho de produtividade se deu em decorrência do avanço na mecanização, da utilização de novas técnicas de produção, a instalação de empresas mais eficientes na região, além do mais a alteração do regime cambial de fixo para flutuante desvalorizou a moeda brasileira aumentando sua competitividade ante aos concorrentes internacionais. Destacam-se também no período o prosseguimento da expansão do comércio mundial que também contribuiu positivamente, com $69,60 \%$. No entanto, o efeito destino, comparando com o período anterior, permaneceu negativo, alertando para a perda de share nos mercados tradicionais do melão potiguar.

No terceiro subperíodo, foi observado o maior crescimento efetivo (54\%) dentre todos os períodos analisados. Este desempenho está relacionado às contribuições positivas em todos os efeitos, com destaque significativo para o efeito da competitividade, com $70,41 \%$. Esse efeito pode estar relacionado à forte desvalorização cambial que ocorreu no ano de 2002, variação de cerca de 50\% em relação à cotação anual de 2001. Apesar da queda de $18 \%$ em 2003, a taxa de câmbio só retorna aos patamares de 2001 no ano de 2005. Neste subperíodo, o efeito destino passou a colaborar positivamente para o crescimento efetivo, devido ao crescimento da participação do melão potiguar em alguns dos seus principais parceiros, como por exemplo, o crescimento da participação no mercado holandês de cerca de $8 \%$ no total das importações de melão daquele país. 
No quarto subperíodo, todos os efeitos permaneceram positivos, o que representou um crescimento efetivo de $40 \%$. Todavia houve uma redução da participação do efeito competitividade como fonte de crescimento efetivo, o fator passou a representar apenas $27,19 \%$. Nos demais efeitos, o comportamento foi inverso, ou seja, ocorreu aumento na participação de ambos, com destaque para o efeito destino, o qual passou de $6,44 \%$ para $34,04 \%$.

No quinto subperíodo, apresenta-se uma forte retração da participação dos melões potiguares no mercado global, um decrescimento efetivo de $36 \%$. Tal resultado é decorrência das retrações dos efeitos de competitividade e mercados de destino, os quais contribuíram em montantes de $98,69 \%$ e 7,20\%, respectivamente ${ }^{6}$. O desempenho negativo do efeito destino pode estar associado aos sinais de crise econômica global que se alastrou na Europa e atingiu o Reino Unido, um dos principais parceiros do RN, que diminuíram em $13 \%$ sua importação de melão, e também a redução drástica na participação nas importações holandesa, caindo metade do que era em 2005/2007. Entretanto, percebe-se que o comércio mundial agiu de forma contrária a esse cenário, mesmo assim o crescimento do comércio mundial de melão não conseguiu contribuir significativamente para evitar este desastroso desempenho.

Por sua vez, o péssimo desempenho da competitividade da produção do estado se deve em grande parte ao fechamento de uma das principais empresas produtoras de melão no estado, ao passo que a maior incerteza na economia mundial coincidiu com o período da safra 2008/2009 (agosto a março) (OLIVEIRA, 2011). Além da crise internacional, o ano de 2008 também foi marcado pela queda da produção em consequência de eventos climáticos, pois o Vale do Açú sofreu fortes inundações, prejudicando a produção agropecuária (ANUÁRIO, 2009).

No sexto subperíodo, o desempenho desfavorável permanece, porém com um decrescimento efetivo nas exportações do melão potiguar inferior ao observado no período anterior, queda de $1 \%$. O efeito competitividade foi o aquele que mais colaborou para esta redução, representando uma retração de 554,76\%. O comércio mundial também contribuiu positivamente para esse cenário, queda de $4,25 \%$. No entanto, o efeito destino atuou de forma contrária, com $-459 \%$, o que significa que os principais parceiros comerciais do RN apresentaram taxa média de crescimento das importações superior ao crescimento do comércio mundial.

${ }^{6} \mathrm{O}$ fato de os valores apresentarem sinal positivo na tabela significa que eles contribuíram positivamente para o resultado, que foi uma retração. 


\subsection{Decomposição das Fontes de Crescimento das Exportações de Melão no Ceará}

Tabela 2 - Síntese dos resultados da CMS do CE

\begin{tabular}{lcccc}
\hline \multicolumn{1}{c}{ Período } & $\begin{array}{c}\text { Crescimento } \\
\text { Efetivo }\end{array}$ & Competitividade & $\begin{array}{c}\text { Crescimento do } \\
\text { Comércio Mundial }\end{array}$ & Efeito Destino \\
\hline $\begin{array}{l}1993 / 95- \\
1996 / 98(\mathrm{I})\end{array}$ & $99,00 \%$ & $76,85 \%$ & $44,42 \%$ & $-21,27 \%$ \\
\hline $\begin{array}{l}1996 / 98- \\
1999 / 01(\mathrm{II})\end{array}$ & $616,00 \%$ & $99,15 \%$ & $1,9 \%$ & $-1,06$ \\
\hline $\begin{array}{l}1999 / 01- \\
2002 / 04(\mathrm{III})\end{array}$ & $190,00 \%$ & $90,06 \%$ & $6,59 \%$ & $3,36 \%$ \\
\hline $\begin{array}{l}2002 / 04- \\
2005 / 07(\mathrm{IV})\end{array}$ & $52,00 \%$ & $48,52 \%$ & $29,48 \%$ & $22,00 \%$ \\
\hline $\begin{array}{l}2005 / 07- \\
2008 / 10(\mathrm{~V})\end{array}$ & $79,00 \%$ & $101,68 \%$ & $2,65 \%$ & $-4,33 \%$ \\
\hline $\begin{array}{l}2008 / 10- \\
2011 / 13\end{array}$ & $-7,00 \%$ & $190,65 \%$ & $0,82 \%$ & $-91,46 \%$ \\
\hline
\end{tabular}

Fonte: Elaboração própria, a partir de dados do ALICEWEB/MDIC e FAOSTAT/FAO.

Observa-se de maneira geral analisando a tabela 2 que o Ceará manteve um crescimento expressivo e consistente ao longo de quase todo o período analisado, com exceção dos últimos 3 anos da série (2011-13). Percebe-se que, no primeiro subperíodo exportações do melão cearense praticamente dobrou, registrando uma expansão de mercado de $99 \%$. Tal movimento foi possível devido ao impacto da expansão do comércio global de alimentos a partir de meados da década de 1990, como referido anteriormente, que representou um avanço de mais de $40 \%$. Porém, foi o fator competitividade o principal responsável por tamanha expansão, apresentando um resultado de 76,85\%. Por outro lado, observou-se que o efeito destino $(-21,27 \%)$ se comportou contrariamente a esse incremento, ou seja, o estado não concentrou suas exportações de melão para mercados com crescimento dinâmicos. A implementação do sistema de Produção Integrada de Frutas (PIF) e da Secretaria de Agricultura Irrigada (SEAGRI) no final dos anos 1990 e a instalação de uma grande empresa, a Agrícola Famosa, no município de Icapuí/CE podem ter influenciado significativamente para esse cenário positivo. 
No segundo subperíodo, apresentou-se uma ainda maior ampliação da participação do Ceará no mercado internacional, um crescimento de $616 \%$. Outra vez o principal fator responsável por tal expansão são os ganhos de competitividade que contribuiu com 99,15\% para esse comportamento, o que significa ganhos de participação das exportações de melão nos diferentes mercados, uma vez que o crescimento do comércio mundial durante este perído apesar de positivo foi bastante tímido, apenas 1,9\%. Esse ganho de competitividade pode ser decorrente da isenção de ICMS dada pelo Governo Estadual que de acordo com Viana et al. (2008) passou a vigorar a partir de 2001 e teve impactos importantes no setor. $\mathrm{O}$ efeito destino permaneceu negativo $(-1,06)$, porém com uma taxa bem menor que o observado anteriormente.

O movimento de expansão da parcela de mercado do melão cearense continuou a todo vapor no terceiro subperíodo, sendo que desta vez todos os efeitos contribuíram positivamente para o desempenho do crescimento efetivo de $190 \%$. Contudo, o efeito competitividade continuou sendo o propulsor do desempenho positivo sendo responsável por $90,06 \%$. O efeito destino das exportações foi responsável por apenas 3,36\% do crescimento efetivo.

No quarto subperíodo, o crescimento efetivo permaneceu positivo (52\%), porém com uma taxa bem inferior ao observado anteriormente. Todos os efeitos contribuíram para esse aumento, com destaque para o efeito competitividade que colaborou com $48,52 \%$. No quinto subperíodo, o efeito competitividade continuou sendo a mais importante fonte para o desempenho positivo das exportações de melão, com 101,68\%. O efeito destino agiu de forma contrária ao crescimento efetivo, uma das causas para esta contribuição negativa, foi a consequência da crise internacional no Reino Unido (um dos maiores importadores do produto) que reduziu quase $13 \%$ de sua importação. No entanto, mesmo com esse cenário, o Ceará conquistou espaços nos mercados, destacando sua competitividade mesmo com as quedas nas quantidades importadas.

No sexto subperíodo, que compreende os anos de 2011 a 2013 a trajetória de expansão da parcela de mercado das exportações cearenses é interrompida. Observa-se uma perda de mercado 7\%, tal fato é resultado do mau desempenho da competitividade responsável por uma forte redução e também pelo efeito do crescimento do comércio mundial, com $0,82 \%$. O efeito destino procedeu de forma contrária a esse cenário, que pode ser explicado pelo crescimento de $14 \%$ das importações da Holanda, seu principal destino. 


\subsection{Comparação das Fontes de Crescimento das Exportações de Melão do Rio Grande Do Norte e do Ceará}

Um dos pontos mais evidentes na comparação dos estados foi que durante quase todo o período analisado, exceto o sexto subperíodo, o crescimento efetivo das exportações do melão cearense foi impulsionado pelo aumento da competitividade do estado no mercado internacional. No caso das exportações do melão potiguar, o crescimento efetivo apesar de ganhos de competividade terem sido responsáveis por expansão de fatias de mercados em alguns subperíodos, observa-se que o crescimento mundial do comércio do melão foi o principal fator que permitiu ganhos de share pelo Rio Grande do Norte ao longo do período analisado.

No ano de 2008, o mundo vivenciou uma crise econômica internacional que afetou todos os setores da economia. O efeito desta crise pode ser observado no quinto subperíodo das exportações do melão potiguar. No entanto, neste mesmo período, o melão cearense apresentou crescimento efetivo, o que significa que o estado não sofreu os impactos profundos da crise internacional de 2008. Esse crescimento cearense pode ser decorrente dos incentivos fiscais fornecidos pelo governo estadual, o que não ocorreu no estado potiguar (ANUÁRIO, 2009). Tal fato inclusive impacta na migração de algumas empresas para território cearense.

\section{Considerações Finais}

Este trabalhou buscou explicar o comportamento do crescimento efetivo das exportações de melão cearense e potiguar durante o período de 1993 a 2013, fase em que se observou um crescimento expressivo de $558 \%$ na receita. Para obter essa análise foram utilizados dados (em toneladas) referentes às importações de melão, tanto mundiais como dos principais parceiros, e também das exportações de ambos os estados, aplicando-se o método Constant Market Share (CMS), que responsabiliza as mudanças que ocorrem no crescimento efetivo das exportações aos efeitos de crescimento (ou decrescimento) do comércio mundial, destino das exportações e competitividade.

Em termos de resultados, o método CMS permitiu inferir que o crescimento efetivo das exportações do melão cearense, e também o decrescimento no sexto subperíodo, foi ocasionado pelo efeito competitividade. O ganho de competitividade está relacionado às condições internas favoráveis, o que de fato aconteceu no estado do CE, cujo estado adotou e criou incentivos para o desenvolvimento da agricultura irrigada e para a expansão das exportações, principalmente para a fruticultura, com a criação da Secretaria de Agricultura Irrigada (SEAGRI), a implementação da Produção Integrada de Frutas (PIF), a introdução de novas técnicas de produção, e a redução da carga tributária imposta ao produto no ano de 2001. No caso potiguar, o crescimento efetivo das 
exportações do melão também foi influenciado pelo efeito competitividade, porém, o crescimento do comércio mundial também determinou o crescimento efetivo, no primeiro e quarto subperíodo. No entanto, esse resultado indica que exportações que dependem do crescimento da demanda externa estão mais propícias às flutuações, pois os números de parceiros comerciais podem diminuir.

O crescimento do melão brasileiro foi bastante animador no período considerado, mesmo sofrendo grandes perdas na crise econômica mundial de 2008. A quantidade exportada ainda não recuperou o valor alcançado antes da grande crise, mas voltou a crescer após o ano de 2011.

O aumento da produção do melão cearense e potiguar nos últimos anos pode estar relacionado ao aumento da produtividade, ultrapassando 20 toneladas por hectare no final da dos anos 1990, superando a produtividade do melão brasileiro em quase todo o período estudado, exceto o ano de 1996 que o melão cearense ficou um pouco abaixo. O uso intensivo de tecnologias na agricultura, as novas técnicas de produção e a disseminação de novos conhecimentos agrícolas foram fundamentais nesse aumento de produtividade.

Os resultados foram positivos em quase todo o período observado, excetos os últimos subperíodos, em virtude da crise mundial. Entretanto, o setor frutícola ainda carece de muitos investimentos que proporcione uma melhor produção e que evite o desperdício, através da questão do transporte, ao passo que boa parte dos transportes utilizados para escoar as frutas não é apropriada para transportarem alimentos perecíveis.

Outro fator determinante para a produção do melão seria a disponibilidade de água, pois o Nordeste, devido ao seu clima seco, está sujeito a sofrer fenômenos naturais, como a seca, por exemplo, em decorrência do aquecimento global, resultando numa diminuição da oferta de água. Em suma, a produção do melão pode ser diretamente prejudicada pelos fatores naturais presentes na região.

Com base nos dados levantados e na literatura estudada, fica evidente que não existe diferença entre os estados cearense e potiguar, à medida que a produção do melão ocorre numa região localizada na divisa de ambos os estados. Deste modo, o que acaba atraindo a instalação das empresas são os incentivos e isenções fornecidas pelo estado e também a questão hídrica.

\section{Referencial Bibliográfico}

ANUÁRIO BRASILEIRO DE FRUTICULTURA. Rio Grande do Sul: Gazeta, 2014. 140 p. Rio Grande do Sul: Gazeta, 2009. 71 p Rio Grande do Sul: Gazeta, 2006. 71 p. . Rio Grande do Sul: Gazeta, 2005. 71 p. 
CARNEIRO, Ricardo. Desenvolvimento em crise: a economia brasileira no último quarto do século XX. Unesp, 2002.

CARVALHO, M. A.; LEITE, C. R. Mudanças na pauta das exportações agrícolas brasileiras. Revista de Economia e Sociologia Rural, Rio de Janeiro, v. 46, n. 1, p. 53-73, jan./mar. 2008.

CEARÁ. Secretaria da Agricultura Irrigada. Irrigando para a competitividade:

PROCEAGRI - Programa cearense da agricultura irrigada. Fortaleza: SEAGRI, 2000

CELIN E. F.; PASTORI PL; NUNES GHS; ARAGÃO FAS. Agronegócio brasileiro do melão na última década. Revista Horticultura Brasileira, v. 31, n. 2, p. S0246 - S0253, 2014.

DORNELES, Tathiane Marques; CALDARELLI, Carlos Eduardo. Desempenho das Exportações Brasileiras e Sul-Mato Grossenses do Complexo Soja: uma análise de constant-marketshare. Revista Econômica, v. 15, n. 2, 2014.

FERRÃO, André Munhoz de Argollo; BRAGA, Luci Mehry Martins; POZZER, Carlos Eduardo. Os Perímetros Irrigados do Baixo Jaguaribe no estado do Ceará [Brasil]: uma experiência referencial de projeto territorial sustentável. Confins. Revue franco-brésilienne de géographie; Revista franco-brasilera de geografia, n. 21, 2014.

FIGUEIREDO, Adelson Martins; DOS SANTOS, Maurinho Luiz; LÍRIO, Viviani Silva. ANÁLISE DE MARKET-SHARE E FONTES DE VARIAÇÃO DAS EXPORTAÇÕES BRASILEIRAS DE SOJA. Revista de Economia e Agronegócio-REA, v. 2, n. 3, 2004.

FUNCKE, A.; MIRA, E.; MASCARENHAS, G., ;PEREIRA, P. Sistema Produtivo 04: Perspectivas do Investimento em Agronegócio, Rio de Janeiro: UFRJ, 2009.

JÚNIOR, Orlando Gonçalves; FERREIRA, Léo da Rocha; ARAÚJO, Paulo Fernando Cidade de. Determinantes da Balança Comercial do Complexo Agroindustrial Brasileiro. (Syn) thesis, v. 5, n. 2, p. 143-155, 2012.

LEAMER, E. E.; STERN, R. M. Models of comparative export performance. Yale Economic Essays, v. 7, p. 103-45, 1970.

LEAMER, E. E.; STERN, R. M. Quatitative internacional economics.2 ed. New Jersey: Transaction Publisher, 2008.

MARANHÃO, Rebecca Lima Albuquerque; VIEIRA FILHO, José Eustáquio Ribeiro. A dinâmica do crescimento das exportações do agronegócio brasileiro. Texto para discussão IPEA, 2016.

NUNES, E. M. Reestruturação agrícola, instituições e desenvolvimento rural no nordeste: as dinâmicas regionais e a diversificação da agricultura familiar no polo Assu-Mossoró (RN). Tese de Doutorado apresentada no Programa de desenvolvimento Rural da UFRGS, Porto Alegre: UFRGS, 2009.

NUNES, Emanoel M.; SCHNEIDER, S. A dinâmica desigual do desenvolvimento regional no Nordeste: o pólo Assu/Mossoró (RN). In: CONGRESSO DA SOCIEDADE BRASILEIRA DE ECONOMIA, ADMINISTRAÇÃO E SOCIOLOGIA RURAL, 46., 2008. Anais... 2008.

OLIVEIRA, A. C. Competitividade e parcela de mercado: Uma abordagem Constant-MarketShare para a soja em grão brasileira (2000-2011). Minas Gerais: Vaginha, 2014.

OLIVEIRA, E. P. de. Arranjos produtivos globalizados: o caso do APL da fruticultura de Melão de Mossoró/Baraúna-RN. Dissertação (Mestrado em economia) - Universidade Federal do Rio Grande do Norte, Programa de Pós Graduação em Economia, Natal, 2011. 
PENHA, Thales Augusto M.; OLIVEIRA, P. R. S.. A evolução do comércio agroalimentar mundial e seus impactos no Polo Açú-Mossoró: uma abordagem de redes. In: CONGRESSO DA SOCIEDADE BRASILEIRA DE ECONOMIA, ADMINISTRAÇÃO E SOCIOLOGIA RURAL, 53, 2015, João Pessoa. Anais... 2015.

PENHA, T.; BELIK, W.; MATOS FILHO, J; OLIVEIRA, G. Measuring value capture along the Brazilian melon value chain. In.: Decent work deficits in southern agriculture: measurements, drivers and strategies. Eds. Christoph Scherrer \& Santosh Verma. Augsburg: Rainer Hampp Verlag, 2018.

PENHA, T.; Estrutura e Dinâmica do Sistema Agroalimentar Mundial: Uma Análise dos Mercados de Fruticultura dos Pólos Irrigados de Açú-Mossoró e Petrolina-Juazeiro. Mauritius: Novas edições acadêmicas, 2018.

PLOEG, J.D. Van Der.; VAN DIJK, G. (eds.) Beyond modernization: the impact of endogenous rural development. Netherlands, Assen: Van Gorcum, 1995.

RICHARDSON, D. J. Constant market-shares analysis of export growth. Journal of International Economics, v. 1, n. 2, p. 227-239, 1971.

SILVA, Pedro Carlos Gama da. Articulação dos interesses públicos e privados no pólo Petrolina-PE/Juazeiro-BA: em busca de espaço no mercado globalizado de frutas frescas. 2001. Dissertação (Doutorado em economia) - Universidade Estadual de Campinas, SP, 2001.

SILVA, J. L. M Da; MARTINS, J. S. Competitividade e parcela de mercado: Uma Análise do Constant Market Share para o Mercado de Camarão Brasileiro. Revista Economica do Nordeste (REN), v. 43, n. 1, p. 129-131, jan./mar. 2012. Disponível em: https://ren.emnuvens.com.br/ren/article/view/197. Acesso em: 3 de 2017.

SOARES, Rogério Barbosa. Análise da sustentabilidade da cadeia produtiva do melão: O caso do agropolo baixo Jaguaribe-Ceará. Tese de Doutorado apresentada 2009.

THORSTENSEN, V. OMC-Organização Mundial do Comércio: as regras do comércio internacional e a nova rodada de negociações multilaterais. São Paulo: Aduaneiras, 2003.

Tyszynski H. World Trade in Manufactured Commodities, 1899-1950 1. The Manchester School. 1951 Sep;19(3):272-304.

VASCONCELLOS, Marco Antônio Sandoval de; GREMAUD, Amaury Patrick; TONETO JR, Rudinei. Economia brasileira contemporânea. São Paulo: Atlas, 1999.

VIANA, Sciena Servia et al. Competitividade do Ceará no mercado internacional de frutas: o caso do melão. Revista Ciência Agronômica, v. 37, n. 1, p. 25-31, 2008.

WILKINSON, J. Mercados, redes e valores: o novo mundo da agricultura familiar. Porto Alegre: UFRGS, 2008. 